\title{
AVALIAÇÃO DA INFLUÊNCIA DO FORMOL E DO HIPOCLORITO DE SÓDIO NA PESQUISA DE OOCISTOS DE CRYPTOSPORIDIUM NAS FEZES, ATRAVÉS DO MÉTODO DE HEINE
}

\author{
José Rafael Módolo, Vicente Amato Neto, Lúcia Maria Almeida Braz, Carlos \\ Alberto Magalhães Lopes e Arnold Frederico Gottschalk
}

\begin{abstract}
Foram examinadas, para pesquisa de Cryptosporidium pelométodo de Heine, fezes de nove bezerros com criptosporidíase, após utilização prévia de dois diferentes desinfetantes. Quanto ao formol a 10\%, notou-se que não houve interferência na identificação dos oocistos, em periodo compreendido entre cinco minutos e 72 horas; ao ser usado o hipoclorito de sódio a $14,5 \%$, verificou-se que depois de 30 minutos os oofistos apresentaram-se avermelhados esem refração, dificultando o reconhecimento. Assim, recomenda-se a adição de formol a $10 \%$ à matéria fecal, conforme a etapa referida, para coibir o risco de infecção de laboratoristas pelo vírus da imunodeficiência humana (HIV), quando usada para diagnóstico a técnica mencionada.
\end{abstract}

Palavras-chaves: Criptosporidiase. Método de Heine. Desinfetantes. Inativação do vírus da imunodeficiência humana (HIV).

A criptosporidíase é enteropatia causada pelo Cryptosporidium, coccídeo cuja ação no intestino promove atrofia, colabamento e destruição das vilosidades, motivando diarréia como conseqüência ${ }^{13}$.

O primeiro caso humano descrito foi o de uma criança imunocompetente, com enterocolite ${ }^{12}$. Posteriormente, relatou-se o encontro do parasita em indivíduos afetados por doença imunossupressiva ou tendo a imunidade deprimida como resultado de quimioterapia, mas também detectou-se a protozoose em pessoas sem aparentes distúrbios imunológicos ${ }^{14}$ 19. Mais recentemente, os "Centers for Disease Control" notificaramo encontro do Cryptosporidium em fezes de enfermos acometidos pela síndrome da imunodeficiência adquirida (AIDS) e isso tornou a pesquisa de oocistos imprescindivel nas tentativas relacionadas à definição etiológica e instituição de

\footnotetext{
Faculdade de Medicina Veterinária e Zootecnia de Botucatu e Instituto de Biociências de Botucatu, da Universidade Estadual Paulista, Botucatu, SP e Laboratório de Investigação MédicaParasitologia, do Hospital das Clínicas, da Faculdade de Medicina da Universidade de São Paulo, São Paulo, SP.

Endereço para correspondência: Dr. José Rafael Módolo. Laboratório de Planejamento de Saúde Animal e de Saúde Pública. Distrito de Rubião Júnior. Caixa Postal 524, 18600400 , Botucatu, SP, Brasil.
}

Recebido para publicação em 05/10/93. tratamento ${ }^{4}$.

Observações colhidas no âmbito da Medicina veterinária revelaram que o Cryptosporidium, em bezerros com diarréia, pode não estar associado a qualquer outro agente enteropatogênico e que, outrossim, tem-se encontrado oocistos em animais quando a citada manifestação clínica está ausente $^{9} 10$. Contudo, é importante salientar que a inoculação experimental do protozoário em diferentes espécies de vertebrados revelou que ele não é espécie-específico, convindo ainda lembrar que a criptosporidíase corresponde a expressiva zoonose ${ }^{14} 18$.

A infecciosidade do vírus da imunodeficiência humana (HIV), desencadeador da AIDS, passou a suscitar extremo rigor na manipulação de fezes humanas durante a rotina laboratorial, uma vez que esse microorganismo, por vezes presente em tecidos intestinais do reto e do duodeno, pode ser eliminado por processo de descamação ${ }^{11}$. Tal fato estimulou a efetivação deste estudo, destinado a contribuir para a proteção dos que analisam matérias fecais que eventualmente contêmo HIV. Para tanto, procurouse juntar às amostras, procedentes de bezerros, inativadores do vírus, avaliando possivvel influência na eficácia do método de diagnóstico proposto por Heine 678111517 . 
Módolo JR, Amato Neto V, Braz LMA, Lopes CAM, Gottschalk AF. Avaliação da influência do formol e do hipoclorito de sódio na pesquisa de oocistos de Cryptosporidium nas fezes, através do método de Heine. Revista da Sociedade Brasileira de Medicina Tropical 27:75-77, abr-jun, 1994.

\section{MATERIAL E MÉTODOS}

Foram examinadas, em 14 diferentes periodos de tempo, duas alíquotas de fezes individuais de nove bezerros com diarréia, contendo mais de $1,5 \times 10^{6}$ oocistos/g ${ }^{16}$. Acrescentou-se, separadamente a cada uma, partes iguais de formol a $10 \%$ e solução de hipoclorito de sódio a $14,5 \%$, de acordo com norma para desinfecção seguida em setor hospitalar de isolamento ${ }^{2}$. Os exames sucederam aos cinco e dez minutos; depois, tiveram lugar a cada 15, até serem completadas duas horas, com novas procuras decorridas $12,24,48$ e 72 horas. Houve antes centrifugação a 3.000r.p.m. durante cinco minutos e, desprezando-se o sobrenadante, ocorreu apreciação do sedimento por intermédio da técnica de Heine, baseada fundamentalmente na refração de oocistos em óleo de imersão, em seqüência à coloração pela fucsina de Ziehl, que faz o Cryptosporidium mostrar-se de forma acromática e tendo brilho característico ao microscópio ótico ${ }^{6}$.

\section{RESULTADOS}

Em todas as etapas mencionadas, nas quais as fezes estiveram sob a ação do formal a $10 \%$, verificou-se a não interferência na identificação dos oocistos, que permaneceram com a estrutura, o tamanho, o formato redondo ou elipsóide, o caráter acromático e a refração característicos. A única alteração digna de registro deu-se na coloração de fundo do esfregaço, pois ela passou a ser azul. Relativamente ao hipoclorito de sódio a $14,5 \%$, comprovou-se que depois de 30 minutos os oocistos perdem a refração e aparecem avermelhados, dificultando a diferenciação, mesmo estando preservada a morfologia.

\section{DISCUSSÃO}

Atualmente, não há mais dúvidas acerca do papel do Cryptosporidium como agente causador etiológico de enteropatia em seres humanos e animais, existindo paralelamente diversas técnicas preconizadas para diagnóstico, combase na detecção de oocistos ${ }^{3}{ }^{10}$. Na presente pesquisa, optou-se por utilizar o método proposto por Heine, interpretado como simples e capaz de propiciar, com rapidez, seguro reconhecimento da forma parasitária em apreço ${ }^{6}$.

Considerando-se as seríssimas conseqüências da infecção pelo HIV, assim como o perigo de contaminação de laboratoristas, é imperioso propor medidas preventivas sem dúvidas eficientes. A preocupação vinculada à segurança instou-nos a avaliar o valor de dois produtos, mantendo como enfoque eventual prejuízo concernente à observação dos oocistos e rememoramos que o formol já foi alvo de idêntica especulação em face de outras técnicas ${ }^{1}$. Esse desinfetante e o hipoclorito de sódio inativam retrovírus, figurando nesse contexto o HIV; concentrações são tidas como válidas e escolhemos as que mais comumente suscitam preferências onde exercemos atividades 781517 .

Levando-se em conta essa particularidade e diante dos resultados que tivemos, afigura-se apropriado sugerir adição prévia do formol a $10 \%$, porque protege quem executa o processo idealizado por Heine, a par de viabilizar armazenamento por até 72 horas, sem gerar contratempos pertinentes ao diagnóstico ${ }^{6}$.

O fato de termos executado as verificações com fezes de bezerros não invalida as conclusões porque o Cryptosporidium de origem humana não difere do albergado por animais ${ }^{14}$.

Quando enviados a laboratórios, os materiais destinados a exames só às vezes contêm a indicação de positividade para HIV e muitos infectados não estão reconhecidos ou até escamoteiam a condição, inclusive podendo faltar o informe, recomendando cautela. Em face de tudo isso, surge a necessidade de generalizar o cuidado preventivo.

Aproveitamos a oportunidade para considerar a obrigatoriedade, presentemente, de incluir nas análises rotineiras técnica apta a diagnosticar a criptosporidíase, sem que pedido explícito tenha lugar. Essa parasitose é hoje, razoavelmente, disseminada e não mais incomum ou excepcional.

\section{SUMMARY}

Cryptosporidium oocysts were searched by Heine's method in stools of nine calfs with cryptoporidiosis after stool treatment with two disinfectants, $10 \%$ paraformaldehyde solution and $14,5 \%$ sodium hypochlorite solution. After 30 minutes exposition to sodium hypochlorite solution oocysts became non refractile and acquired a reddish tinge, making their identification 
Módolo JR, Amato Neto V, Braz LMA, Lopes CAM, Gottschalk AF. Avaliação da influência do formol e do hipoclorito de sódio na pesquisa de oocistos de Cryptosporidium nas fezes, através do método de Heine. Revista da Sociedade Brasileira de Medicina Tropical 27:75-77, abr-jun, 1994.

difficult. No morphological alterations occured in oocysts after paraformaldehyde treatment. We recommend paraformaldehyde at $10 \%$ concentration as means of human immunodeficiency virus (HIV) inactivation for routine use in stool examinations and therefore making safer those type of procedures for laboratory personnel, when using Heine's method.

Key-words: Cryptosporidiosis. Heine's method. Disinfectants. Human immunodeficiency virus (HIV) inactivation.

\section{AGRADECIMENTOS}

A Dra. Lúcia R. Souza e aos servidores Adriana C. Pavan, Tânia Martins e Wanderley Forlin pela colaboração prestada.

\section{REFERÊNCIAS BIBLIOGRÁFICAS}

1. Amato Neto V, Braz LMA, Campos R, Ogassawara S, Motta HMC, Morandi NF, Marques HHS. Avaliação da influência do formol na pesquisa de Cryptosporidium $s p$. nas fezes, através do método de Sheather e do "Coprotest". Revista do Hospital das Clínicas da Faculdade de Medicina de São Paulo 47:231-233, 1992.

2. Amato Neto V, Corrêa LL. Exame parasitológico das fezes. $4^{\text {a }}$ edição, Sarvier, São Paulo, 1980.

3. Bird RG, Smith MD. Cryptosporidiosis in man: parasite life cycle and fine structural pathology. Journal of Pathology 132:217-233, 1980.

4. Centers for Disease Control. Cryptosporidiosis: assessment of chemotherapy of males with acquired immune deficiency syndrome (AIDS). Morbidity and Mortality Weekly Report 31:589-592, 1982.

5. Centers for Disease Control. Update: treatment of cryptosporidiosis in patients with acquired immunodeficiency syndrome (AIDS). Morbidity and Mortality Weekly Report 33:117-119, 1984.

6. Heine J. Eine einfache Nachweismethode für Kryptosporidien im Kot. Zentralblatt für Veterinärmedizin 29:324-327, 1982.

7. Martin LS, LoskoskiSL, McDougal JS. Inactivation of human T-lymphotropic virus type III/ lymphadenopathy-associated virus by formaldehydebased reagents. Applied and Environmental Microbiology 53:708-709, 1987.

8. Martin LS, McDougal JS, Loskoski SL. Disinfection and inactivation of human T-lymphotropic virus type III/lymphadenopathy-associated virus. The Journal of Infectious Diseases 152:400-403, 1985.

9. Modolo JR, Gonçalves RC, Kuchembuck MRG, Gottschalk AF. Ocorrência de criptosporidiose em bezerros na região de Botucatu-SP. Revista Brasileira de Medicina Veterinária 10:9-10, 1988.

10. Moon HW, Bemrick WJ. Fecal transmission of calf cryptosporidia between calves and pigs. Veterinary Pathology 18:248-255, 1981.

11. Nelson JA, Reynolds-Kohler C, Margaretten W, Wiley CA, Reese CE, Levy JA. Human immunodeficiency virus detected in bowel epithelium from patients with gastrointestinal symptoms. The Lancet I:259-262, 1988.

12. Nime FA, Burek JD, Page DL, Holscher MA, Yardley JH. Acute enterocolitis in a human being infected with the protozoan Cryptosporidium. Gastroenterology 70:592-598, 1976.

13. Pohlenz J, Bemrick WJ, Moon HW, Cheville NF. Bovine cryptosporidiosis: a transmission and scanning electron microscopic study of some stages in the life cycle and of the host-parasite relationship. Veterinary Pathology 15:417-427, 1978.

14. Reese NC, Current WL, Ernst JV, Bailey WS. Cryptosporidiosis of man and calf: a case report and results of experimental infections in mice and rats. The American Journal of Tropical Medicine and Hygiene 31:226-229, 1982.

15. Resnick L, Veren K, Salahuddin SZ, Tondreau S, Markham PD. Stability and inactivation of HTLVIII/LAV under clinical and laboratory enviroments. The Journal of the American Medical Association 255:1887-1891, 1986.

16. Schultz W. Die bovine Kryptosporidiose-Nachweis und Bedeutung. Monatsheft Veterinär-Medizin 41:330-335, 1986.

17. Spire B, MontagnierL, Barré-Sinoussi F, Chermann JC. Inactivation of lymphadenopathy associated virus by chemical disinfectants. The Lancet II:899901, 1984.

18. Tzipori S, Angus KW, Campbell I, Gray EW. Cryptosporidium: evidence for a single-species genus. Infection and Immunity 30:884-886, 1980.

19. Weisburger WR, Hutcheon DF, Yardley JH, Roche JC, Hillis WD, Charache P. Cryptosporidiosis in an immunosupressed renal-transplant recipient with IgA deficiency. The American Journal of Clinical Pathology 72:473-478, 1979. 